\title{
ANALISIS INOVASI PELAYANAN PUBLIK "KELAS PERAHU" KABUPATEN PANGKAJENE DAN KEPULAUAN
}

\author{
Dian Sari \\ Program Studi Informatika, Universitas Indraprasta PGRI \\ dian.sari@unindra.ac.id
}

\begin{abstract}
Abstrak
Kelas Perahu merupakan salah satu inovasi pelayanan publik di bidang pendidikan yang mendapatkan penghargaan Top 40 Inovasi Pelayanan Publik 2018. Kelas perahu ditujukan untuk mengurangi jumah angka putus sekolah di pulau-pulau yang berada di Kabupaten Pangkajene dan Kepulauan. Selama satu tahun diimplementasikan Angka Partisipasi Sekolah (APS) di Kabupaten Pangkajene dan Kepulauan pada tingkat Sekolah Dasar mencapi 100 persen dan tingkat Sekolah Menengah Pertama (SMP) naik sebesar 1.16 persen. Indonesia merupakan negara kepulauan yang memungkinkan kelas perahu untuk dapat ditingkatkan lagi kualitasnya dan dapat digunakan di daerah kepulauan lainnya, oleh karena itu dalam penelitian ini bertujuan untuk menganalisis inovasi pelayanan kelas perahu dari sisi pengertiannya, keberhasilan kelas perahu dan menganalisis dari sudut pandang post managerial. Analisis dilakukan dengan menggunakan metode desk research yaitu mengumpulkan data-data sekunder hingga penarikan kesimpulan dengan metode kualitatif deskriptif. Dari hasil penelitian yang dilakukan, kelas perahu merupakan inovasi pelayanan di bidang pendidikan yang baru, bermanfaat, dan sesuai dengan harapan publik, kemudian dapat dilanjutkan lagi dengan menjadikan kelas perahu bukan sekedar memenuhi program wajib belajar pemerintah, namun juga harus berpengaruh kepada sektor lainnya.
\end{abstract}

Kata Kunci inovasi, pelayanan publik,kelas perahu.

\begin{abstract}
Kelas Perahu is one of the public service innovations in the education sector that received the Top 40 Public Service Innovation 2018 Award. Kelas Perahu are intended to reduce the number of drop-out rates on the islands in the Pangkajene and Islands Districts. For one year the School Participation Rate (APS) was implemented in Pangkajene and Kepulauan Districts at the Primary School level, reaching 100 percent and the junior high school level rose by 1.16 percent. Indonesia is an archipelagic country that allows Kelas Perahu to be able to improve their quality and can be used in other islands, therefore in this study aims to analyze Kelas Perahu service innovations in terms of understanding, success of Kelas Perahu and analyzing from a post managerial perspective. Analysis is carried out using the desk study method, which collects secondary data to draw conclusions with descriptive qualitative methods. From the results of the research conducted, the Kelas Perahu is a service innovation in education that is new, useful, and in accordance with public expectations, then can be continued by making the boat class not only fulfilling the government's compulsory education program, but also influencing other sectors.
\end{abstract}

Keywords: Innovation, Public Service, Kelas Perahu.

\section{PENDAHULUAN}

Berdasarkan Pasal 31 Undang-Undang Dasar Republik Indonesia setelah amandemen keempat, disebutkan "Setiap warga negara berhak mendapatkan pendidikan dan Setiap warga negara wajib mengikuti pendidikan dasar dan pemerintahan wajib membiayainya." Pendidikan dasar merupakan suatu kebutuhan yang harus dipenuhi oleh pemerintah kepada warga negaranya di Indonesia. Dalam undang - undang sistem pendidikan nasional Bab VI Pasal 17 disebutkan bahwa pendidikan dasar merupakan jenjang pendidikan yang melandasi jenjang pendidikan menengah. Pendidikan dasar berbentuk Sekolah Dasar (SD) dan Madrasah Ibtidaiyah (MI) atau bentuk lain yang sederajat serta Sekolah Menengah Pertama (SMP) dan Madrasah 
Tsanawiyah (MTS) atau bentuk lain yang sederajat.

Pada Tahun Ajaran 2017/2018 Angka Putus Sekolah Tingkat Sekolah Dasar di Indonesia mencapai 32. 127 dari 25.486.506 jumlah siswa lama di seluruh sekolah dasar di Indonesia atau sekitar 0,13 persen [1], yang berarti rangking Indonesia masih di bawah Malaysia dan Thailand [2]. Dalam mengurangi angka putus sekolah di Indonesia, maka diperlukan inovasi pelayanan publik dalam dunia pendidikan. Pelayanan publik merupakan kewajiban konstitusional negara, jadi Pemerintah berkewajiban menyelenggarakan pelayanan publik yang sebaik-baiknya kepada masyarakat. Inovasi pelayanan publik merupakan kumpulan ide dan gagasan yang dijadikan terobosan untuk meningkatkan kualitas pelayanan publik. Kelas Perahu merupakan salah satu inovasi pelayanan publik yang mendapatkan penghargaan Inovasi Pelayanan Publik Top 40 di Bidang Pendidikan se-Indonesia pada tahun 2018. Inovasi tersebut merupakan salah satu kontribusi Kabupaten Pangkajene dan Kepulauan (Pangkep) untuk memberikan layanan pendidikan bagi anak pulau yang sembari membantu orang tuanya. Setelah berjalannya kelas perahu selama satu tahun, kelas perahu telah dapat meningkatkan Angka Partisipasi Sekolah (APS) SD/MI menjadi 100 persen, dan APS SMP/MTS sebesar 1,16 persen.

\begin{tabular}{cllllll} 
Tabel 1. Angka Partisipasi Sekolah di Kabupaten Pangkejene dan Kepuauan \\
\cline { 2 - 4 } & $\mathbf{2 0 1 5}$ & & $\mathbf{2 0 1 6}$ & & $\mathbf{2 0 1 7}$ & \\
Umur & Laki-Laki & Peremppuan & Laki-Laki & Peremppuan & Laki-Laki & Peremppuan \\
\hline $\mathbf{7 - 1 2}$ & 98.18 & 100.00 & 98.65 & 100.00 & 100 & 100 \\
$\mathbf{1 3 - 1 5}$ & 76.16 & 91.65 & 89.53 & 89.85 & 85.61 & 96.08 \\
$\mathbf{1 6 - 1 8}$ & 60.74 & 46.70 & 56.83 & 70.99 & 58.40 & 70.00 \\
\hline
\end{tabular}

Sumber: Badan Pusat Statistik Kabupaten Pangkejene dan Kepulauan Tahun 2016 - 2018

Peningkatan APS di usia Sekolah Dasar membuktikan bahwa inovasi pelayanan pendidikan kelas perahu sangat membantu menurunkan angka putus sekolah di Kabupaten Pangkep. Kelas perahu dapat dikembangkan dan diimplementasikan ke daerah-daerah kepulauan lainnya, sehingga APS di tingkat pendidikan dasar Indonesia dapat mencapai 100 persen. Berdasarkan keberhasilan kelas perahu dalam meningkatkan APS di Kabupaten Pangkep, maka dalam penelitian ini ditujukan untuk menanalisis inovasi pelayanan publik kelas perahu di Kabupaten Pankajene dan Kepulauan. Dari hasil analisis diharapkan dapat memberikan manfaat di bidang pendidikan dalam meningkatkan inovasi kelas perahu agar dapat juga diimplementasikan di daerah-daerah kepulauan Indonesia lainnya, dan juga berhasil pada meraih APS 100 persen di tingkat SMP/MTS dan SMA di Indonesia sehingga menuntaskan program wajib belajar pemerintah guna mencerdaskan kehidupan bangsa.

\section{Pengertian Inovasi Pelayanan Publik}

Inovasi sebagai sesuatu yang baru yaitu dengan memperkenalkan dan melakukan praktek atau proses baru (barang atau layanan) atau bisa juga dengan mangadopsi pola baru yang berasal dari organisasi lain [3]. Inovasi merupakan pengenalan sesuatu yang baru ke dalam sebuah sistem, akan tetapi tidak selalu seperti itu, dalam keadaan tertentu dan dengan aplikasi (seringkali intervensi) dari sebuah ide baru. Inovasi tersebut menghasilkan sebuah proses transformasi yang membawa sesuatu yang terputus dari subjeknya (seperti produk atau layanan) dan atau lingkungannya (seperti organisasi, pasar 
atau komunitas) [4]. Perubahan-perubahan yang layak diakui sebagai inovasi harus baru bagi organisasi, cukup besar, cukup umum dan cukup tahan lama untuk mempengaruhi operasi atau karakter organisasi [5].

\section{Kriteria Inovasi Pelayanan Publik yang Berhasil}

1. Meningkatkan nilai publik dalam kualitas, efisiensi, atau kesesuaian untuk tujuan pemerintahan atau layanan [6].

2. Meningkatkan respon layanan terhadap kebutuhan lokal dan individu; Memenuhi kebutuhan dan harapan publik[4].

3. Manfaat dari suatu inovasi pelayanan publik dinilai sebagai esensi inovasi. Manfaat bagi masyarakat dapat dilihat dari kemudahan dalam pelayanan yang cepat, mudah atau praktis, dan murah [7].

\section{Peningkatan Kualitas Inovasi}

Inovasi publik adalah suatu penerapan gagasan baru ke dalam satu atau berbagai aspek dari pelayanan publik yang bisa memberikan nilai tambah. Oleh karena itu harus ada perubahan yang positif dari penerapan inovasi sehingga tercipta nilai tambah yang diharapkan. Setelah implementasi inovasi pelayanan publik, alur selanjutnya adalah mengetahui manfaat dan nilai tambah dari inovasi pelayanan tersebut[7]. Nilai dalam pelayanan publik, menururt Cole dan Parston [8] disebutkan bahwa lebih dari sekedar pencapaian output ataupun mereduksi biaya. Inovasi pelayanan publik yang berhasil harus mampu ditingkatkan kualitasnya dan dikembangkan untuk diimplementasikan kedaerah ataupun organisasi lainnya. Dalam penelitian ini, peningkatan kualitas pelayanan publik dilihat dari cara memandang pelayanan publik kelas perahu di pada era setelah inovasi pelayanan publik kelas perahu diimplementasikan, oleh karena itu peningkatan kualitas pelayanan publik dilihat terlebih dahulu dari kriteria era yang identik dengan kelas perahu saat diimplementasikan di Kabupaten Pangkep. Analisis peningkatan kualitas inovasi pelayanan publik kelas perahu agar dapat berkelanjutan, menggunakan analisis inovasi dalam administrasi publik, berikut penjelasannya:

Tabel 2. Evolusi Inovasi dalam Administrasi Publik

\begin{tabular}{|c|c|c|c|c|}
\hline & \multicolumn{4}{|c|}{ Evolusi } \\
\hline & $\begin{array}{l}\text { Private Sector } \\
\text { Origins }\end{array}$ & $\begin{array}{l}\text { Classic Public } \\
\text { Administration } \\
\text { Canouns }\end{array}$ & $\begin{array}{l}\text { New Public } \\
\text { Management }\end{array}$ & $\begin{array}{c}\text { Post-managerial } \\
\text { Avenues }\end{array}$ \\
\hline $\begin{array}{l}\text { Pengertian } \\
\text { Inovasi }\end{array}$ & $\begin{array}{l}\text { cara baru untuk } \\
\text { membuat nilai tambah } \\
\text { ekonomi }\end{array}$ & $\begin{array}{l}\text { Ancaman terhadap } \\
\text { mekanisme lama yang } \\
\text { dapat diandalkan }\end{array}$ & $\begin{array}{l}\text { Cara baru untuk } \\
\text { menanggapi warga } \\
\text { sebagai klien dan } \\
\text { menghasilkan } \\
\text { barang publik }\end{array}$ & $\begin{array}{l}\text { Cara-cara baru untuk } \\
\text { menciptakan } \\
\text { kesejahteraan sosial } \\
\text { dan psikologis, } \\
\text { surplus ekonomi, dan } \\
\text { stabilitas politik }\end{array}$ \\
\hline $\begin{array}{l}\text { Siapa yang } \\
\text { menjadi } \\
\text { penerima } \\
\text { manfaat } \\
\text { utama dari } \\
\text { inovasi }\end{array}$ & $\begin{array}{l}\text { Pemilik perusahaan } \\
\text { dan klien }\end{array}$ & $\begin{array}{l}\text { Sektor swasta dan elit } \\
\text { sosial }\end{array}$ & $\begin{array}{l}\text { Warga sebagai } \\
\text { klien / pelanggan }\end{array}$ & $\begin{array}{l}\text { masyarakat secara } \\
\text { keseluruhan }\end{array}$ \\
\hline $\begin{array}{l}\text { Bagaimana } \\
\text { cara } \\
\text { mencapai } \\
\text { inovasi }\end{array}$ & $\begin{array}{l}\text { Meningkatnya } \\
\text { otonomi kerja, tingkat } \\
\text { partisipasi yang lebih } \\
\text { tinggi dalam }\end{array}$ & $\begin{array}{l}\text { Hampir tidak perlu; } \\
\text { birokrasi gaya klasik } \\
\text { tidak benar-benar } \\
\text { membutuhkan inovasi }\end{array}$ & $\begin{array}{lr}\text { Kontak } & \text { intensif } \\
\text { dengan } & \text { sektor } \\
\text { swasta } & \text { dan } \\
\text { peningkatan } & \end{array}$ & $\begin{array}{l}\text { Kontak global yang } \\
\text { intensif dengan } \\
\text { inovator } \\
\text { internasional, }\end{array}$ \\
\hline
\end{tabular}




\begin{tabular}{|c|c|c|c|c|}
\hline $\begin{array}{l}\text { pengambilan } \\
\text { keputusan, } \\
\text { pemberdayaan } \\
\text { budaya }\end{array}$ & $\begin{array}{r}\text { dan } \\
\text { kerja }\end{array}$ & $\begin{array}{lr}\text { dan melihat diri } \\
\text { mereka sebagai pulau } \\
\text { stabilitas } & \text { dan } \\
\text { konservatisme } & \end{array}$ & $\begin{array}{l}\text { pembelajaran dari } \\
\text { inovator yang } \\
\text { sukses di } \\
\text { perusahaan bisnis }\end{array}$ & $\begin{array}{l}\text { pembandingan, } \\
\text { pembelajaran dan } \\
\text { persaingan program } \\
\text { kebijakan }\end{array}$ \\
\hline
\end{tabular}

Sumber: International Public Management Journal, Volume 8 Nomor 1 Tahun 2005

\section{METODE PENELITIAN}

Penelitian ini menggunakan metode desk research, yaitu studi literatur dengan analisis deskriptif. Pengumpulan data dilakukan dengan memanfaatkan data sekunder yang tersedia dari berbagai literatur. Pertama, mengumpulkan literatur hasil-hasil penelitian sebelumnya yang berkaitan dengan tema penelitian ini, dan didukung dengan berbagai artikel jurnal, dan buku serta informasi lain yang relevan. Kedua, melakukan pemilahan data sesuai dengan tema dan fokus studi ini. Ketiga, mendeskripsikan analisis inovasi pelayanan publik di lokus studi ini beserta di unit atau daerah lain sebagai pembanding. Selanjutnya adalah penarikan kesimpulan dilakukan dengan metode induktif, yaitu generalisasi dari berbagai fenomena yang diperoleh dari Analisis Inovasi pelayanan publik yang menyerupai dengan kelas perahu. Penelitian ini berangkat dari fenomena pemberian penghargaan Kelas Perahu sebagai Top 40 Inovasi Pelayanan Publik Tahun 2018.

\section{HASIL DAN PEMBAHASAN \\ Inovasi Pelayanan Publik "Kelas Perahu"}

Kelas perahu adalah suatu inovasi pelayanan publik bukan merupakan sesuatu yang baru dalam sistem pendidikan di Indonesia, banyak layanan pendidikan yang memliki kemiripan dengan kelas perahu, yaitu:

a. Pada tahun 2009 lalu ada sebuah program bernama Perahu Pembelajaran yang dilegkapai sejumlah fasilitas kegiatan belajar bagi warga belajar kejar paket. Fasilitas tersebut terdiri perputakaan, buku modul, seperangkat alat audio visual, serta komputer.
Fungsinya menjadi tempat edukasi sekaligus perpustakaan keliling anatar pulau di Kecamatan Gili Genting, Kabupaten Sumenep.

b. Di Bangladesh ada Sekolah terapung. Sekolah terapung dibuat oleh LSM untuk membantu anak-anak supaya tetap memperoleh pendidikan dikala banjir melanda rumah mereka, sekolah perahu juga menjadi fasilitas klinik kesehatan, perpustakaa, bahkan pusat pelatihan pertanian [9];

c. Perahu Pustaka yaitu program yang bertujuan membawa buku-buku anak yang menyenangkan ke desa nelayan terpencil dan pulau-pulau kecil di kawasan angka melek huruf yang rendah dan kegemaran membaca yang tidak ada. Program ini dilakukan oleh M. Ridwan Alimuddin pada tahun 2015 di Sulawesi Barat [10];

d. Program Sopo dan Kabar Belajar yang dibentuk Yayasan Alusi Tao Toba pada 18 Juni 2009 bertujuan untuk memudahkan akses informasi dan memberikan fasilitas pendidikan di kawasan pinggiran Danau Toba. Bistok Manihuruk merupakan salah satu relawan yang berusaha mengenalkan pendidikan kepada anak-anak samosir di empat desa di empat kecamatan di sekitaran Danau Toba [11];

Kelas Perahu mengahasilkan sebuah transformasi pendidikan. Pendidikan di Sekolah dasar yang biasanya diadakan di ruang kelas saja, kini diubah oleh gagagsan Ibu Rukmini. Belajar di sebuah perahu, di tengah lautan sembari membantu orang tua 
yang dapat dilakukan kapan saja, pagi, siang, malam, ataupun subuh hari. Kelas perahu melakukan transformasi pendidikan khususnya di Sekolah Dasar Negeri 23 Pulau Sakuala Wialayah III Kecamatan Liukang Tupabbiring Utara namun tetap bertujuan yang sama yaitu menyediakan pendidikan dasar bagi anak pulau di Kabupaten Pangkep.

\section{Keberhasilan "Kelas Perahu"}

1. Peningkatan kualitas pendidikan di Kabupaten Pangkep, yang ditandai bahwa anak-anak usia SD mencapai APS 100 persen dan APS usia sekolah tingkat SMP meningkat dari tahun 2016 dari 89.69 menjadi 90.85. Anak-anak Sekolah Dasar dapat menamatkan pendidikan mereka dan anak-anak tingkat SMP dapat meningkatkan keinginan mereka untuk terus bersekolah walaupun anak-anak tersebut ikut membantu orang tuanya bekerja. Hal tersebut merupakan hal yang merupakan kiteria keberhasilan suatu inovasi publik karena dinilai menunjukkan peningkatan kualitas. Inovasi pelayanan publik Kelas Perahu juga bersesuaian dengan tujuan negara yaitu mencerdaskan kehidupan bangsa.

2. Kelas perahu dinilai merupakan pemenuhan dari harapan publik. Pada tahun 2014 di Kabupaten Pangkep, ijazah yang paling banyak di tamatkan adalah SD, dan hanya berjumlah 27,99 persen, dan rata-rata anak usia SD tamat selama 7, 31 tahun dari normalnya 6 tahun. Anak-anak nelayan membutuhkan pelayanan pendidikan yang lebih pro aktif dari gurunya agar mereka tida putus sekolah. Di anakanak kelas tinggi, kelas 4, 5, 6 rata-rata yang putus sekolah $2-3$ persen tiap tahun dengan adanya kelas perahu tidak ditemuan lagi anak-anak yang putus sekolah. (Abd.Muin, A.Md-Koordinator Pendidikan Dasar Kecamatan Liukang).
Harapan publik anak-anak pulau di Pulau Sakuala adalah dapat bersekolah walaupun ikut membantu orang tua di laut, hal tersebut dapat dipenuhi dengan adanya kelas perahu pada November 2016, anak-anak pulau dengan leluasa bias mengikuti kelas belajar walaupun sedang di laut dengan sarana Lembar Siswa yang sudah dimodifikasi oleh menurut silabus kelas regular, silabus dimodifikasi sesuai dengan situasi dan kondisi anak-anak di kelas perahu sehingga anak itu tidak ketinggalan.

3. Manfaat kelas perahu menjadikan anakanak pulau yang ikut membantu orang tuanya bekerja tidak ketinggalan pelajaran di kelas. Mereka dapat belajar di perahu dan di ruang kelas. Guru dengan pro aktif membantu dengan memberikan tugas di Lembar Siswa dan mengoreksi juga menjelaskan materi setelah anak0anak tersebut kembali ke darat. Jika anak-anak tersebut tidak melautpun mereka diperbolehkan untuk dating ke sekolah bergabung dengan temannya di ruang kelas seperti biasa untuk mengikuti pelajaran. Kelas perahu memberikan manfaat bagi sekolah-sekolah yang berada di pulau Kabupaten Pangkajene. Program kelas perahu telah berjalan di 19 Sekolah Dasar yang ada di 16 pulau dari 117 pulau yang ada di Kabupaten Pangkep. Dalam setiap pulau hanya memiliki 1-2 Sekolah dasar saja dan beberapa kelas. Namun guru-guru khusunya di Pulau Sakuala sangat berperan penting intuk memberikan kemudahan belajar bagi anak-anak pulau, pelayanan yang cepat, mudah dan tidak berbayar. Namun diperlukan kebijakan dari Pemerintah Kabupaten Pangkep untuk memberikan insentif bagi guru-guru sebab mayoritas guru di pulau kabupaten Pangkep adalah guru honorer (guru negeri 20 dan guru honorer 20), guru honorer hanya diberikan gaji $350.000 / 3$ bulan. 


\section{Peningkatan Kualitas "Kelas Perahu"}

Setelah dianalisis, inovasi pelayanan kelas perahu masuk ke dalam inovasi pelayanan publik pada era New Public Management (NPM) sehingga untuk peningkatan kualitas pelayanan, maka inovasi kelas perahu dipandang dari sudut pandang pendekatan Post-Managerial. Analisis ini untuk mengetahui peningkatan kualitas inovasi seperti apa yang diperlukan, agar kelas perahu menjadi inovasi yang berkelanjutan dan diimplemmentasikan di daerah-daerah kepulauan Indonesia maupun organisasi lainnya.

Tabel 3. Analisis Inovasi

\begin{tabular}{|c|c|c|}
\hline & New Public Management & Post Managerial \\
\hline Pengetian Inovasi & $\begin{array}{l}\text { Cara baru untuk menanggapi warga } \\
\text { sebagai klien dan menghasilkan barang } \\
\text { publik }\end{array}$ & $\begin{array}{l}\text { Cara-cara baru untuk menciptakan } \\
\text { kesejahteraan sosial dan psikologis, surplus } \\
\text { ekonomi, dan stabilitas politik }\end{array}$ \\
\hline $\begin{array}{l}\text { Siapa yang menjadi } \\
\text { penerima manfaat } \\
\text { utama dari inovasi }\end{array}$ & Warga sebagai klien / pelanggan & masyarakat secara keseluruhan \\
\hline $\begin{array}{l}\text { Bagaimana cara } \\
\text { mencapai inovasi }\end{array}$ & $\begin{array}{l}\text { Kontak intensif dengan sektor swasta } \\
\text { dan peningkatan pembelajaran dari } \\
\text { inovator yang sukses di perusahaan } \\
\text { bisnis }\end{array}$ & $\begin{array}{l}\text { Kontak global yang intensif dengan } \\
\text { inovator internasional, pembandingan, } \\
\text { pembelajaran dan persaingan program } \\
\text { kebijakan }\end{array}$ \\
\hline
\end{tabular}

Sumber: International Public Management Journal, Volume 8 Nomor 1 Tahun 2005

\section{Inovasi "Kelas Perahu"}

Dalam NPM telah mengubah aturan-aturan ini dan mengidentifikasi inovasi sebagai mesin untuk memacu reformasi (Pollitt dan Bouckaer) [12]. Inovasi sebagai alat yang dapat digunakan organisasi untuk menciptakan cara-cara baru untuk menanggapi warga negara sebagai klien dan menghasilkan barang publik berkualitas lebih tinggi (Osborne dan Gaebler)[12]. Diharapkan bahwa dalam administrasi publik dari era PostManagerial, inovasi akan mengeksplorasi cara-cara baru untuk menciptakan kesejahteraan sosial dan psikologis, bersama dengan stabilitas politik yang melampaui surplus ekonomi belaka. Kelas Perahu hanya merupakan produk yang menargetkan khusus pada bidang pendidikan, belum menjadikan program kelas perahu juga ikut menciptakan kesejahteraan sosial, psikologis, dan stabilitas politik. Sesuai dengan pendekatan Post-Managerial, Inovasi kelas perahu diharapkan dapat:

a. Mengubah pemikiran orang tua dan anak usia belajar bahwa pendidikan kurang penting karena jumlah materi yang didapat dengan menjadi nelayan sehari bisa mencapi 200 hingga 300 ribu.

b. Menaikkan kualitas anak-anak nelayan dengan mengikuti program wajib belajar. Pemerintah harus melakukan modifikasi silabus untuk anak-anak pulau khususnya anak kelas perahu yang memiliki jam belajar dan kegiatan belajar yang berbeda dengan temantemannya. Namun, kualitasnya tetap sama dengan anak-anak regular di Sekolah SD hingga SMP. Pemerintah juga diharapkan membangun sekolah SMA/SMK di daerah-daerah Kepulauan yang berfokus pada pengembangan Sumber Daya Manusia (SDM) yang kompeten untuk bekerja di laut.

\section{Penerima dan Manfaat Inovasi}

Menurut pendekatan NPM, inovasi diinginkan karena memiliki kekuatan untuk meningkatkan layanan kepada warga negara sebagai klien atau pelanggan. Inovasi dilihat sebagai mesin untuk 
pengembangan; energinya harus digunakan dengan cara yang sama digunakan dalam sektor bisnis dalam [4]. Dengan demikian, menurut pandangan Post-Managerial, penerima manfaat inovasi adalah masyarakat, namun bukan hanya warga negara atau kelompok warga, yang akan menuai hasil inovasi (Evans 1996; Rogers 1983) [12]. Inovasi harus dikembangkan dan disebarluaskan kepada warga negara sebagai pemilik layanan publik dan berkontribusi pada kebijakan global dan pengetahuan manajerial (Farazmand 1999) [12].

Kelas perahu masih hanya sebatas memberikan manfaat kepada warga pulau di Kabupaten Pangkep Khususnya di Desa Mattiro Bombang Pulau Sakuala dan Pulau Salemo, yang terdiri dari usia sekolah SD hingga SMP pada usia 7-15 Tahun. Kelas perahu merupakakan inovasi yang sangat baik jika dilanjutkan dan diiimplementasikan di Indonesia, terkait Indonesia memiliki banyak daerah kepulauan yang berjumlah 17.504 buah, 7.870 diantaranya telah mempunyai nama dan 9.634 belum memiliki nama, seperti di Kepulauan Selayar, Pulau, Banyak, Kepualauan Sula dan kepulauan-kepulauan lainnya. Hal tersebut juga diiinginkan dapat menjadikan kelas perahu adalah role model pendidikan di Indonesia khususnya untuk daerah kepulauan yang belum memprioritaskan pendidikan sebagai hal yang utama, dan daerah kepulauan yang memiliki sarana dan prasana yang minim.

\section{Cara Mencapai Inovasi}

Pendekatan NPM menganggap inovasi suatu keharusan, dan bahwa cara terbaik untuk mendorongnya adalah dengan kontak intensif dengan mitra lain di ranah sosio-politik. Mitra utama adalah sektor swasta dan sektor ketiga. Akhirnya, menurut pandangan Post-Managerial cara terbaik untuk mencapai inovasi adalah dengan kontak global yang intensif dengan inovator internasional, benchmarking, dan belajar tentang dan emulasi program kebijakan yang telah terbukti berguna di tempat lain (Vigoda-Gadot 2003b) dalam [4].

Kelas perahu dirintis oleh Ibu Rukmini yang merupakan Kepala Seksi Pendidikan Dasar di Kabupaten Pangkajene dan Kepulauan, dan dibantu oleh pihak pemerintajh Kabupaten dan juga Pihak Pemerintah Australia. Menuju Era PostManagerial, Program Kelas Perahu harus dicapai dengan kontak dengan innovator internasional yang memiliki negara kepulauan dan memiliki masalah yang sama yaitu rendahnya minat belajar di daerah kepulauan, selain melakukan komunikasi dapat pula dengan melakukan studi tentang program pendidikan di daerah kepulauan di Negara lain guna meningkatkan mutu kualitas pendidikan di daerah kepulauan.

\section{SIMPULAN}

Inovasi pelayanan publik "Kelas Perahu" adalah inovasi pelayanan di bidang pendidikan di Kabupaten Pangkajene dan Kepulauan yang berhasil menurunkan angka putus sekolah di tingkat SD/MI dan SMP/MTS. Layanan ini merupakan layanan yang orisinil, bermanfaat bagi anak-anak pulau di Kabupaten Pangkep, dan membantu pemerintah mewujudkan pendidikan dasar. Kelas Perahu untuk keberlanjutannya haruslah layanan yang bermanfaat untuk meningkatkan kesejahteraan sosial, psikologis, surplus ekonomi dan stabilitas politik.

\section{DAFTAR PUSTAKA}

[1] Pusat data Pendidikan dan Kebudayaan, "Ikhtisar Data Pendidikan dan Kebudayaan," Jakarta, 2018.

[2] "Rangking Pendidikan Negaranegara ASEAN | Semua konten media | DW | 17.02.2017,"’ 
DW.COM, 2013. [Online]. Available:

https://www.dw.com/id/rangkingpendidikan-negara-negara-asean/g37594464. [Accessed: 14-Mar2019].

[3] H. Thenint, "Global Review of Innovation Intelligence and Policy Studies - Policy Studies Mini Study 10 Innovation in the public sector," no. February, 2010.

[4] J. Law, "Managing Change And Innovation In Public Service Organisations - Edited by Stephen P. Osborne and Kerry Brown," Public Adm., vol. 84, no. 3, pp. 794796, Aug. 2006.

[5] M. H. Moore, Creating public value: strategic management in government. UK: Harvard University Press, 1997.

[6] T. Brannan, C. Durose, P. John, and H. Wolman, "Assessing best practice as a means of innovation," Local Gov. Stud., vol. 34, no. 1, pp. 23-38, 2008.

[7] D. Sartika, "Inovasi Organisasi Dan Kinerja Organisasi : Studi Kasus Pada Pusat Kajian Dan Pendidikan Dan Pelatihan Aparatur Iii Lembaga Administrasi Negara," J. Borneo Adm., vol. 11, no. 2, Dec. 1969.

[8] A. Wahyudi, "Dari Sudut Tepian Mahakam," no. August 2016, 2017.
[9] Rahayu Andina, "Kalau Indonesia Ada Pasar Terapung, Bangladesh Punya Sekolah Terapung. Patut Kita Contoh Nih!," www.hipwee.com, 2017. [Online]. Available: https://www.hipwee.com/travel/kala u-indonesia-punya-pasar-terapungbangladesh-punya-sekolahterapung-patut-kita-contoh/. [Accessed: 14-Mar-2019].

[10] kompas, "\&quot;Perahu Pembelajaran\&quot;, Perahu untuk Belajar - Kompas.com," kompas.com, 2009. [Online]. Available:

https://lifestyle.kompas.com/read/20 09/07/29/15283345/perahu.pembelaj aran.perahu.untuk.belajar. [Accessed: 14-Mar-2019].

[11] Bempah Triyadi Ramdhan, "Alusi Tao Toba, Jawaban untuk Anakanak di Pinggir Danau Toba Halaman all. - Kompas.com," kompas.com, 2017. [Online]. Available:

https://regional.kompas.com/read/20 17/08/16/13082991/alusi-tao-tobajawaban-untuk- anak-anak-dipinggir-danau-toba-?page $=$ all . [Accessed: 14-Mar-2019].

[12] M. Moore and J. Hartley, "Innovations in governance," Public Manag. Rev., vol. 10, no. 1, pp. 320, Jan. 2008. 